\title{
FAILURE MECHANISM OF SOLID TANTALUM CAPACITORS
}

\author{
B. GOUDSWAARD and F. J. J. DRIESENS
}

\author{
N. V. Philips, Gloeilampenfabrieken, P. D. Elcoma/Development Dept. Eindhoven, Netherlands
}

(Received June 3, 1976, in final form September 30, 1976)

\begin{abstract}
It has been suggested that failure of solid tantalum capacitors is due to thermal migration of impurities from the tantalum anode to flaws in the oxide layer. This implies, however, that leakage current gradually increases under normal operating conditions, an effect which has not been observed. An alternative hypothesis advanced here is that failure is due to crystallization of tantalum oxide under the influence of the electric field. Scanning electron microscopy of specially cleaned anodized tantalum sheet on which thin gold electrodes have been deposited clearly shows the occurrence of crystallization after 17 hours at an applied voltage of $75 \mathrm{~V}$ and a temperature of $65^{\circ} \mathrm{C}$. Results of accelerated life tests on solid tantalum capacitors at temperatures of $85^{\circ} \mathrm{C}$ and $125^{\circ} \mathrm{C}$, and at up to 2,5 times rated voltage also accord better with a field crystallization hypothesis than with a thermal migration failure hypothesis.
\end{abstract}

\section{FAILURE ANALYSIS}

Sudden breakdown failures of solid tantalum capacitors undergoing test are well known. Some breakdowns are followed by healing but result in highly increased leakage current; these are called degradation failures. Others result in a short-circuit; these are called catastrophic failures. No significant increase in leakage current can be observed before most instances of either type of failure.

Predicting the life of solid tantalum capacitors requires an understanding of the failure mechanism. Much work has already been done on breakdown investigation and hypotheses have been advanced, but quantitative treatments to support them are lacking. By collating and analysing this work, we have come to the conclusion that failure in solid tantalum capacitors is due to the field crystallization process, and that the life of the capacitor is determined by the growth rate of the crystal. This paper sets out our reasoning.

\section{$1.1 \quad$ Failure Rate}

By observing the number of failures in a given number of components over a period of time, it is possible to gain an overall picture of component reliability. The failure rate at any instant is expressed as the number of failures at that instant divided by the product of the number of components and the elapsed time. Several such calculations produce the familiar "bath tub" shape life curve shown in Figure 1.

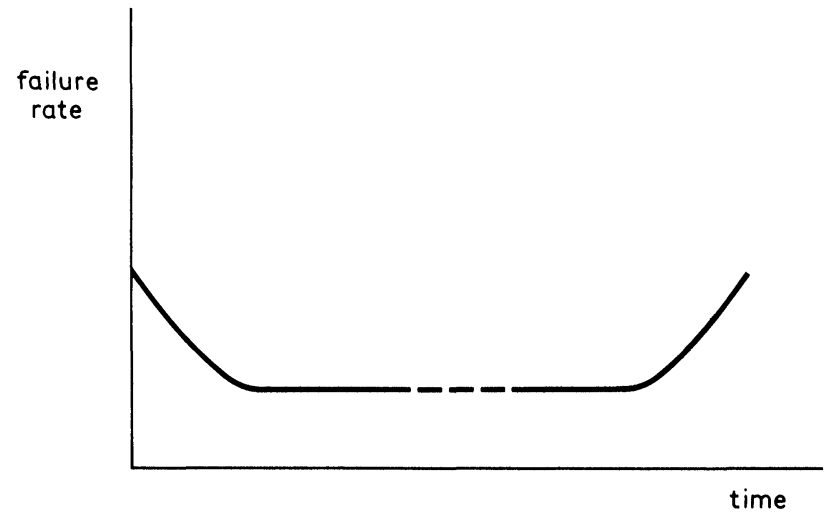

FIGURE 1 Component failure rate with time. Typical "bath tub" curve.

The early failure period of this curve is partly due to manufacturing anomalies and partly to accidental damage during installation and early operation. The final upturn of the curve is the wear-out failure period, in which deterioration processes in the component cause rapidly increasing failure rate. The central constant failure rate period is the useful life of the component, where failures occur at an approximately uniform rate. Our work is concerned with measurements at the wear-out failure period.

\subsection{Accelerated Testing}

Under normal stress conditions the useful life of solid tantalum capacitors is several years; thus the normal 
life-test method is of little help in establishing the failure mechanism. A better method is accelerated testing. At higher stress levels the failure rate increases and the test results lend themselves to more objective analysis.

Catastrophic failure rates show a dependence on applied voltage, temperature and series impedance. ${ }^{1}$ Acceleration factors regarding applied voltage and temperature for Kemet solid tantalum capacitors have been investigated by Didinger. ${ }^{2,3} \mathrm{He}$ suggests that thermal breakdown is initiated by the migration of impurities in the sintered tantalum anode to flaws in the oxide layer, but a quantitative treatment of this process is not given.

\subsection{Breakdown}

Breakdown of a capacitor is characterized by a sudden increase of the leakage current under even circumstances, for instance during a slow increase of voltage. The oxide layer is ruptured when a spark or ionization occurs, after which a higher leakage current prevails.

Breakdown investigations have been conducted by Howard and Smith ${ }^{4}$ and by Burnham. ${ }^{5}$ Their significant findings are:

- The mechanism of breakdown appears to be thermal.

- When healing occurs after a breakdown, an increase in leakage current is observed for all ratings.

- Maximum breakdown voltage is only slightly temperature dependent.

- Maximum breakdown voltage varies between $50 \%$ and $80 \%$ of the forming voltage and is independent of the manufacturer of the capacitor.

- Maximum breakdown voltage decreases with increasing time in step stress tests.

- The duration of breakdown is several milliseconds.

- There is no premonitory noise or significant increase in leakage current prior to breakdown.

- Electron micrographs of breakdown spots, taken after the removal of manganese dioxide, show radial cracks in the oxide layer.

\subsection{Failure Mechanism}

The problem of the failure mechanism, however, is not solved either by failure rate results or breakdown studies. An understanding is therefore necessary of the formation process by which a conducting channel is produced in the oxide layer. In view of the facts, this process has to be a function of time, applied field strength, and temperature.

Didinger's suggestion ${ }^{3}$ that impurities of the anode, impelled by locally higher field strength, will be concentrated at flaws in the oxide film implies a continuously increasing leakage current while a localized heating of the flaw initiates the thermal breakdown. Experimental results do not confirm this idea. ${ }^{6}$

Here we propose that the failure mechanism in solid tantalum capacitors is the field crystallization of tantalum oxide. A quantitative analysis of the published experimental data lends support to this supposition.

\section{FIELD CRYSTALLIZATION}

Field crystallization of anodic tantalum oxide films under wet conditions has been extensively investigated by Vermilyea. ${ }^{8,9}$ Thermal crystallization of amorphous anodic oxide can be achieved at high temperatures. Crystallization can also be achieved below $100^{\circ} \mathrm{C}$ if a strong electric field is applied across the anodic oxide film; this produces circular areas consisting of wedge-shaped polycrystalline segments. The material is an entirely new crystalline film, without consumption of the amorphous phase, pushing back the amorphous film during its growth (Figure 2). Capacitors in Figures 2 to 9 are anodized at $200 \mathrm{~V}$.

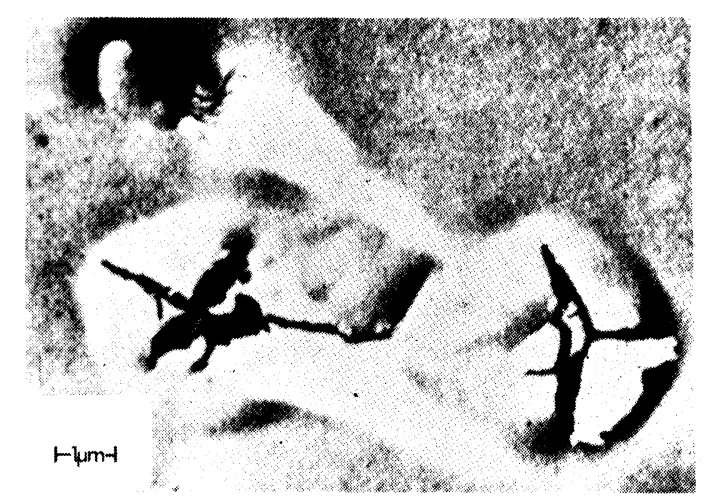

FIGURE 2 Micrograph of the start of crystallization of wet tantalum system (Vermilyea (8)).

Field crystallization occurs only at certain sites on the metal-oxide interface favourable to the formation of crystal nuclei (see Section 3). These favourable sites may be areas of high impurity content in the metal. Vermilyea has analysed the crystal growth as a function of field strength and temperature, and has calculated its activation energy and the distance between the equilibrium positions of the ions.

To confirm the suggestion that field crystallization occurs even in solid capacitors during life test, an attempt was made to detect these crystals. 
A chemically cleaned, sintered tantalum sheet was anodized at $200 \mathrm{~V}$ and thin gold film electrodes of about $2 \mathrm{~mm}^{2}$ were evaporated onto it. These electrodes were only approximately $200 \AA$ thick and not homogenous and therefore it is supposed, would not impede the transport of oxygen or moisture from the air during the test period. The capacitors so formed were first examined with a scanning electron microscope while noting their $\mathrm{x}$ and $\mathrm{y}$ co-ordinates They were then stressed at $70 \mathrm{~V}$ and $65^{\circ} \mathrm{C}$ for a period of 17 hours. Subsequent electron-microscopy revealed that breakdowns had occurred in most of the capacitors and that the resulting damage made detailed examination of the surface impossible. However, on some of those remaining, white spots (possibly crystals of $\mathrm{Ta}_{2} \mathrm{O}_{5}$ ) were discernible after the tests (Figures 3, 4 and 5).

While scanning the surface of the capacitors outside the initially scanned areas, some very clear crystals were observed (Figures 6 and 7). A chance observation of one of these crystals showed that the amorphous film was already cracked, but without

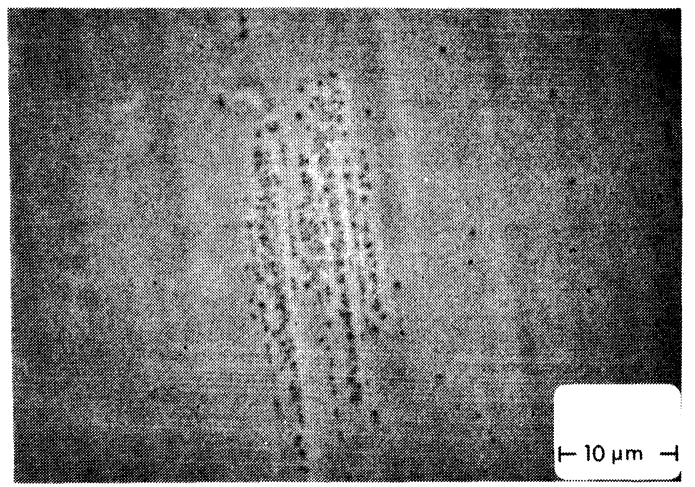

FIGURE 3 Micrograph of oxide surface before life test.

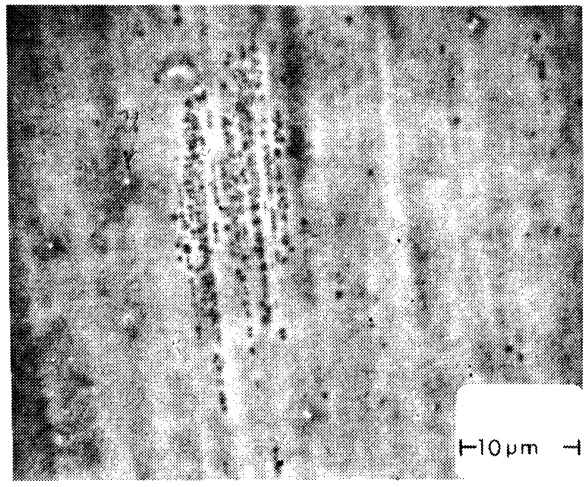

FIGURE 4 Micrograph of oxide surface after life test: incipient crystallization.

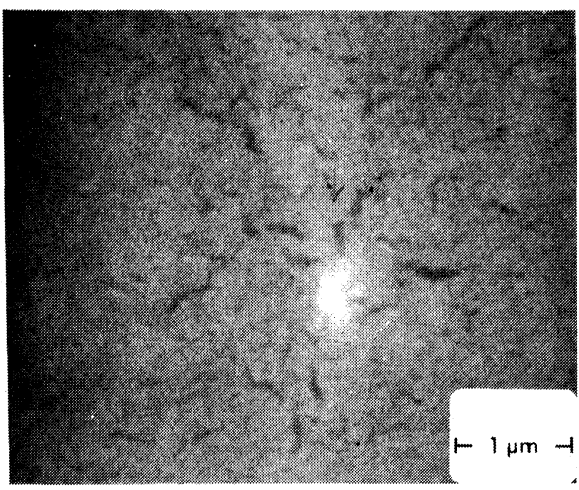

FIGURE 5 Micrograph showing the start of crystallization.

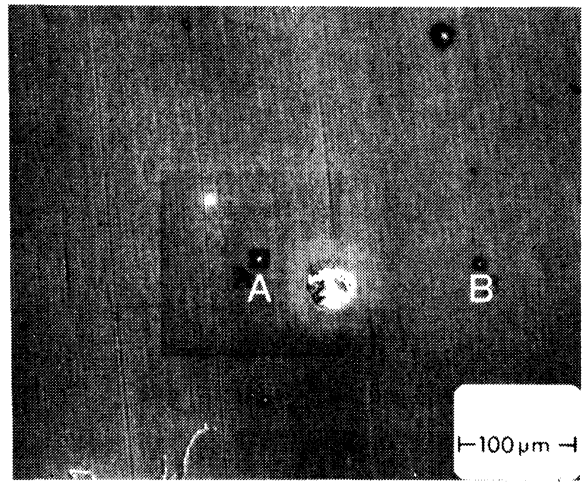

FIGURE 6 Micrograph showing crystalline areas not scanned before life test.

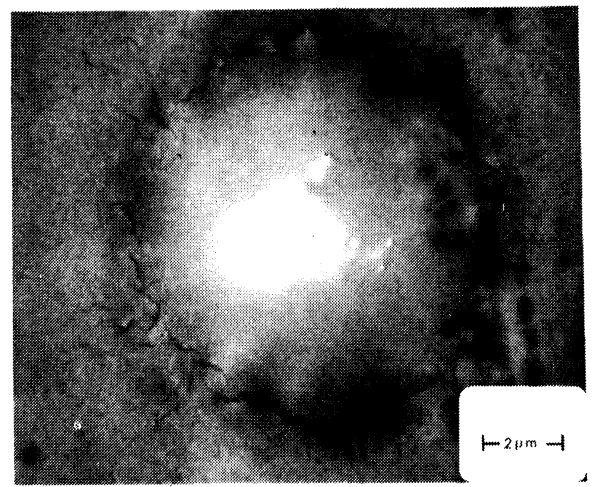

FIGURE 7 Micrograph of the crystalline area A of Figure 6.

breakdown because the gold film on this crystal became insulated (electrically) from the main part of the electrode. This micrograph (Figure 8) is similar in appearance to those by Vermilyea ${ }^{8}$ in wet systems (typical of which is Figure 2) and to those obtained in 


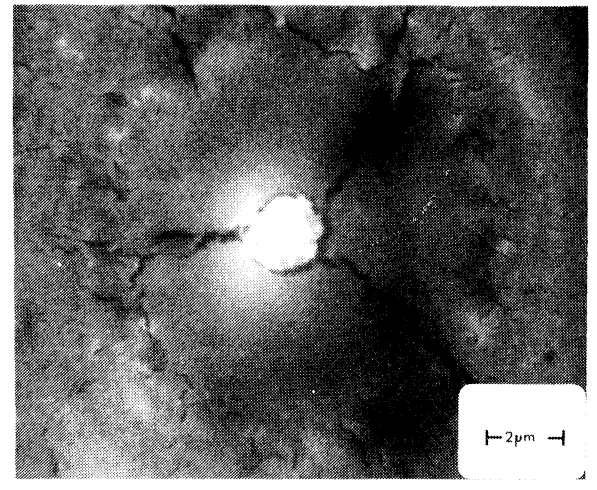

FIGURE 8 Micrograph of the crystalline area B of Figure 6.

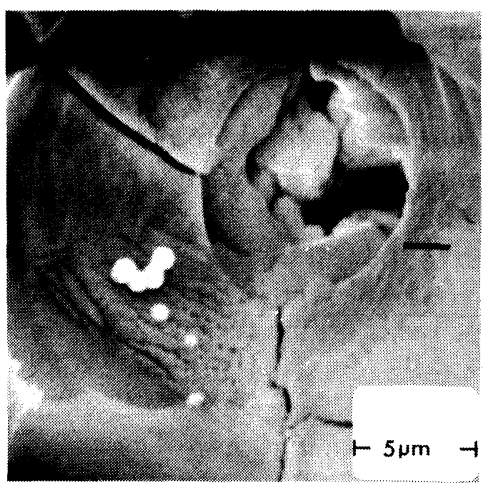

FIGURE 9 Micrograph showing the breakdown area of solid tantalum capacitor with $\mathrm{MnO}_{2}$ electrode (Burnham (5)).

TABLE I

Accelerated test matrix

for $10 \mu \mathrm{F}, 30 \mathrm{~V}$ capacitors

\begin{tabular}{|c|c|c|c|c|c|c|c|c|c|c|}
\hline & \multicolumn{10}{|c|}{ Applied voltage/Working voltage } \\
\hline & 0,83 & 1,0 & 1,17 & 1,33 & 1,67 & 1,83 & 2,0 & 2,17 & 2,33 & 2,5 \\
\hline Temp. $85^{\circ} \mathrm{C}$ & & & 24 & 24 & & & 14 & 27 & 7 & 5 \\
\hline \multirow[t]{2}{*}{ Temp. $125^{\circ} \mathrm{C}$} & 24 & 24 & 16 & 21 & 10 & 17 & 17 & & & \\
\hline & \multicolumn{10}{|c|}{ Sample size } \\
\hline
\end{tabular}

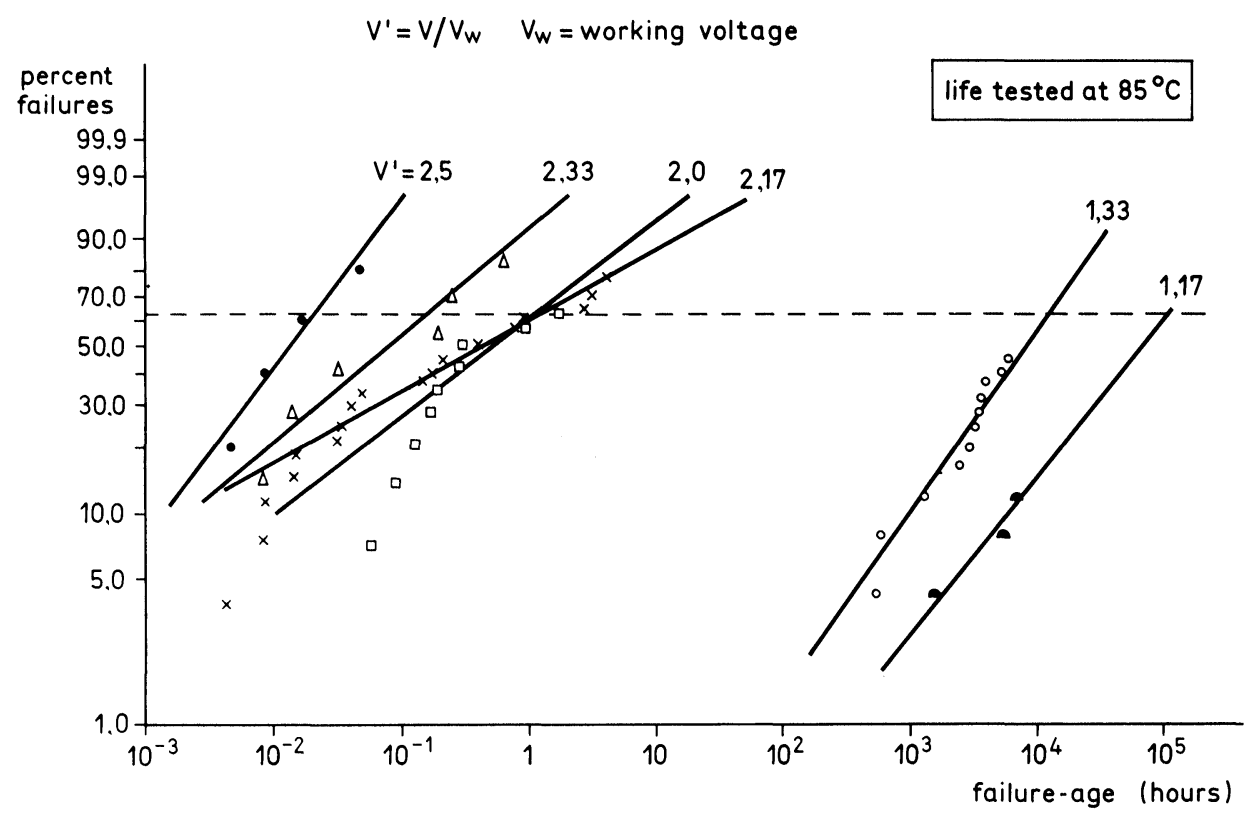

FIGURE 10 Results of G. H. Didinger ${ }^{2}$ for $10 \mu \mathrm{F}, 30 \mathrm{~V}$ tantalum capacitors at $85^{\circ} \mathrm{C}$. 
solid tantalum capacitors with manganese dioxide as cathode (Figure 9), (see Burnham). ${ }^{5}$

These experiments support the idea that field crystallization occurs even in solid tantalum capacitors. It is now proposed that this process accounts for the failures during life test and that, because some critical size of crystal is needed to crack the film, the rate of crystal growth is the factor that determines the failure time of the capacitor.

\section{EXPERIMENTAL DATA}

Examination of experimental data supports this hypothesis. The data given here for mean failure times are from Kemet solid tantalum capacitor reliability studies by G. H. Didinger. ${ }^{2}$ The accelerated tests were made on $10 \mu \mathrm{F}, 30 \mathrm{~V}$ capacitors, style CS14 MIL-C26655/A. Tests were made at $85^{\circ} \mathrm{C}$ and $125^{\circ} \mathrm{C}$, at voltages ranging from 0,833 to 2,5 times the rated value. The accelerated test matrix is given in Table I . Any capacitor whose leakage resistance became equal to its capacitive reactance at $120 \mathrm{~Hz}$ was considered to be a catastrophic failure.

The cumulative percentages of failures against time were plotted on Weibull graph paper (Figures 10 and 11). The slope and intercept parameters define the Weibull distribution function:

$$
F(t)=1-\exp \left(-t / t_{0}\right)^{\beta}
$$

where: $F(t)$ is the cumulative percentage of failures at time $t$

$\beta \quad$ is the shape factor

$t_{0}$ is the scale parameter.

This function can be transformed into a linear equation:

$$
\begin{aligned}
& 1-F(t)=\exp \left(-t / t_{0}\right)^{\beta} \\
& \ln \left(\frac{1}{1-F(t)}\right)=\left(t / t_{0}\right)^{\beta} \\
& \ln \ln \left(\frac{1}{1-F(t)}\right)=\beta\left(\ln t-\ln t_{0}\right)
\end{aligned}
$$

The data are plotted on Weibull paper with $\ln \{1 /(1-F(t)\}$ as ordinate and $\ln t$ as abscissa.

The shape factor or slope of the straight line changes with the shape of the probability density function $f(t)$, the first derivative of the cumulative distribution function $F(t)$. This variation is given in Figure 12.

Failure due to field crystallization usually takes place at flaws in the oxide layer, where field strength is greatest. Each capacitor has many flaws of different size and can be considered as consisting of an equal number of capacitive elements connected in parallel, each having a single flaw. The characteristic life pattern of the capacitor as a whole is then equivalent to that of the weakest element, which is the one with

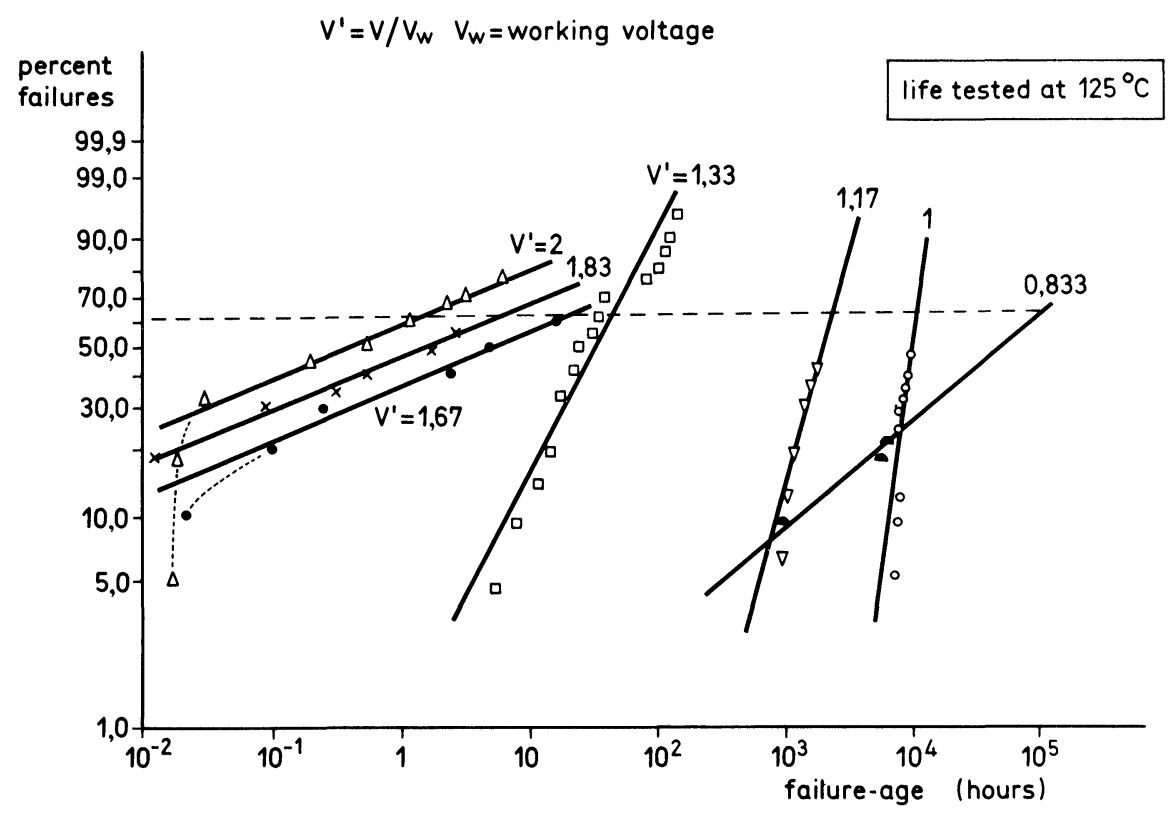

FIGURE 11 Results of G. H. Didinger ${ }^{2}$ for $10 \mu \mathrm{F}, 30 \mathrm{~V}$ tantalum capacitors at $125^{\circ} \mathrm{C}$. 


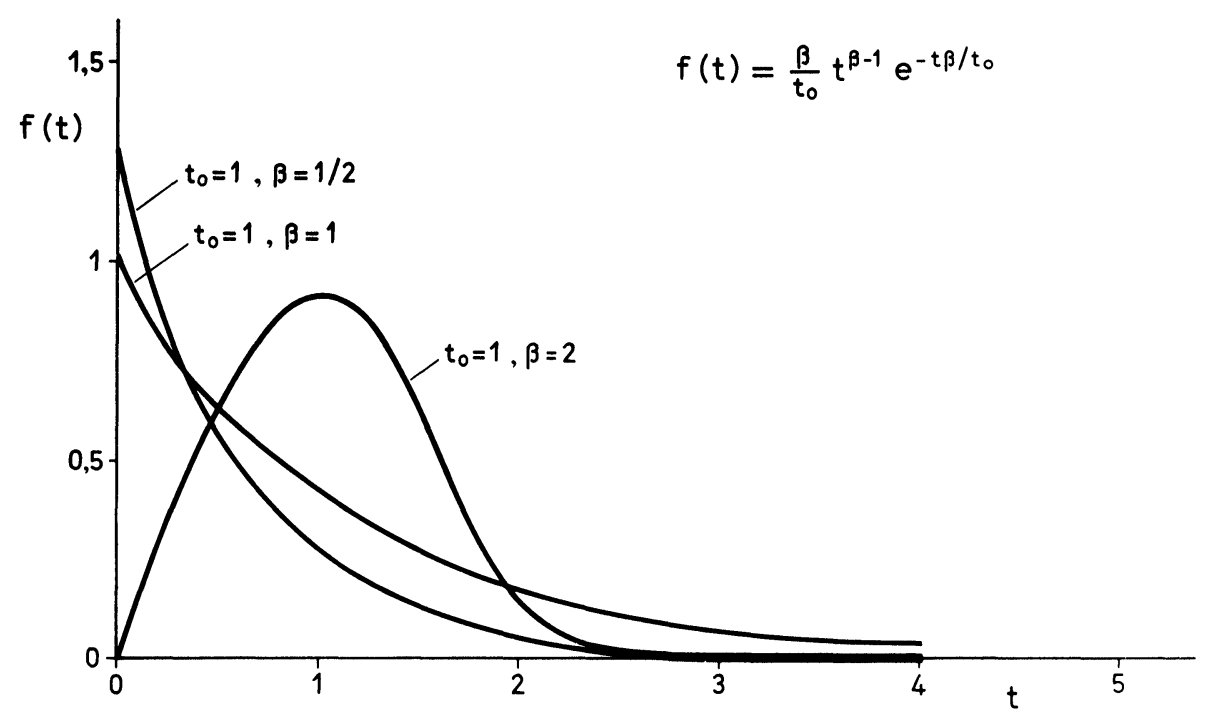

FIGURE 12 Weibull probability density function $f(t)$ with different shape factors $\beta$.

the largest flaw. Normal solid tantalum capacitors have a shape factor $\beta<1$; hence the failure rate decreases with time.

The $63 \%$ Weibull value of cumulative failure represents the characteristic life time. These values are given in Tables II and III; some of the values have been corrected by a better alignment of the data. These times are plotted against the ratio of applied voltage to working voltage $\left(\mathrm{V} / \mathrm{V}_{\mathrm{w}}\right)$ at constant temperature in Figure 13.

The graphs taken from Didinger ${ }^{2}$ in Figure 13 are parallel straight lines which have not been extended to cover the higher stress levels. In the Weibull plots of the higher stress levels the shape factor is too small, which suggests that a different failure mechanism may be encountered at the higher stress levels. In our opinion it is more likely that the probability density

TABLE II

\begin{tabular}{|l|l|l|l|}
\cline { 2 - 4 } \multicolumn{1}{c|}{} & \multicolumn{3}{l|}{$\begin{array}{l}63 \text { percentage Weibull } \\
\text { values of cumulative } \% \\
\text { failed at } 85^{\circ} \mathrm{C}\end{array}$} \\
\hline & $\begin{array}{l}\text { Kemet } \\
\text { values } \\
\text { in hours }\end{array}$ & $\begin{array}{l}\text { Corrected } \\
\text { values } \\
\text { in hours }\end{array}$ & $\begin{array}{l}\text { Total } \\
\text { percentage } \\
\text { failures }\end{array}$ \\
\hline $\mathrm{V} / \mathrm{V}_{\mathrm{w}}$ & $1,2 \times 10^{-1}$ & $2 \times 10^{-2}$ & $80 \%$ \\
2,5 & $3 \times 10^{-1}$ & $1,3 \times 10^{-1}$ & $85 \%$ \\
2,33 & 1,2 & 1 & $80 \%$ \\
2,17 & $6,5 \times 10^{-1}$ & 1,2 & $65 \%$ \\
2,0 & $1,2 \times 10^{4}$ & $1,1 \times 10^{4}$ & $45 \%$ \\
1,33 & $1,1 \times 10^{5}$ & $1,1 \times 10^{5}$ & $12 \%$ \\
1,17 & & & \\
\hline
\end{tabular}

function of failures changes. Figure 12 shows that this function becomes steeper with decreasing shape factor $\beta$. This is understandable because at higher stress levels the probability of healing after a breakdown is smaller.

The solid line graphs in Figure 13, which include the high stress values, are not parallel. This is also understandable because it has been shown ${ }^{5,6}$ that the maximum breakdown voltage is not significantly dependent on temperature, so there must be a crossover of the graphs. From these lines it is seen that the logarithm of the capacitor mean-life time increases approximately linearly with decreasing applied voltage, and that the slope of the line decreases with increasing temperature.

In Section 2, it was proposed that capacitor failure

TABLE III

\begin{tabular}{|c|l|l|l|}
\cline { 2 - 4 } \multicolumn{1}{c|}{} & \multicolumn{3}{|l|}{$\begin{array}{l}63 \text { percentage Weibull } \\
\text { values of cumulative } \% \\
\text { failed at } 125^{\circ} \mathrm{C}\end{array}$} \\
\hline & $\begin{array}{l}\text { Kemet } \\
\text { values } \\
\text { in hours }\end{array}$ & $\begin{array}{l}\text { Corrected } \\
\text { values } \\
\text { in hours }\end{array}$ & $\begin{array}{l}\text { Total } \\
\text { percentage } \\
\text { failures }\end{array}$ \\
\hline $\mathrm{V} / \mathrm{V}_{\mathrm{w}}$ & 1,5 & 1,5 & $75 \%$ \\
1,83 & 3 & 6 & $53 \%$ \\
1,67 & 12 & 18 & $63 \%$ \\
1,33 & 45 & 45 & $95 \%$ \\
1,17 & $2,6 \times 10^{3}$ & $2,4 \times 10^{3}$ & $42 \%$ \\
1 & $1,2 \times 10^{4}$ & $1,1 \times 10^{4}$ & $50 \%$ \\
0,83 & $1,2 \times 10^{5}$ & $1,1 \times 10^{3}$ & $17 \%$ \\
\hline
\end{tabular}




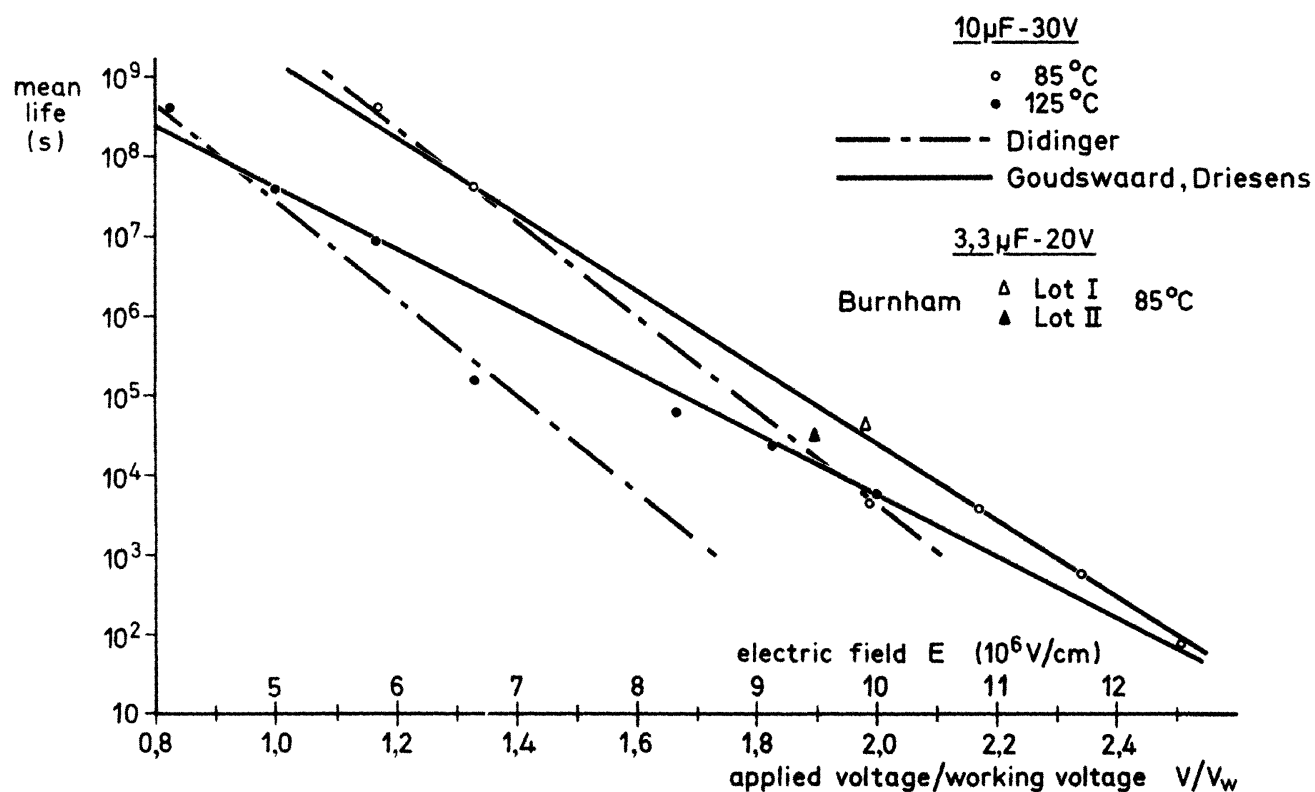

FIGURE 13 Mean-life time vs. applied voltage/working voltage for Kemet $10 \mu \mathrm{F}, 30 \mathrm{~V}$ capactiors at $85^{\circ} \mathrm{C}, 125^{\circ} \mathrm{C}$; for Kemet 3,3 $\mu \mathrm{F}, 20 \mathrm{~V}$ chip capacitors, from Burnham. ${ }^{6}$

time is determined by the rate of growth of a crystal to a critical size at which the film cracks. This growth rate can now be calculated:

$$
\frac{\Delta 1}{\Delta t}=\mathrm{A} \exp \left(-\frac{\mathrm{Q}-\mathrm{qaE}}{\mathrm{kT}}\right)
$$

where: $\mathrm{A}$ is a constant

$Q$ is the activation energy at zero field $\mathrm{q}$ is the charge of the ion

$a$ is the distance from the equilibrium ion position to the top of the potential barrier

$E$ is the electric field, determined by the applied voltage and the thickness of the oxide layer.

$\Delta 1$ is the critical size of the crystal

$\Delta t$ is the time of growth to the critical size.

Since $\Delta 1$ is constant:

$$
\ln \Delta \mathrm{t}=\frac{\mathrm{Q}-\mathrm{qaE}}{\mathrm{kT}}-\ln \mathrm{A}+\ln \Delta \mathrm{l}
$$

This equation shows that the slope of $\ln t$ against $E$ is equal to qa/kT.

The problem now is to transform the applied voltage into electric field strength in the mean-life curve (Figure 13). Vermilyea ${ }^{9}$ has shown that electrical breakdown of anodic tantalum oxide film starts at a flaw in the oxide layer. These flaws occur at places where the growth of the oxide film is impeded by impurities, e.g. carbide or oxide particles which, as previously mentioned, are the points at which field crystallization begins. Figure 14 shows how a typical flaw might appear in cross-section in a $2400 \AA$ film (as given by Vermilyea). This drawing shows how the film thickness at the flaw $\left(d_{\text {flaw }}\right)$ about a quarter of the original thickness $\left(\mathrm{d}_{\mathrm{ox}}\right)$. In this way, the field strength is determined by the oxide film thickness at the site of the flaw.

The working voltage $V_{W}$ of solid capacitors can vary between $1 / 3$ and $1 / 5$ of the forming voltage $V_{F}$. According to measurements made by Burnham ${ }^{5}$ for MIL Style hermetically sealed capacitors, this ratio is approximately $1 / 4$.

The field strength $E_{w}$ for working voltage $V_{w}$ at a flaw can now be written as:

$$
\mathrm{E}_{\mathrm{w}}=\mathrm{E}_{\mathrm{F}}
$$

Since

$$
\frac{\mathrm{V}_{\mathrm{w}}}{\mathrm{V}_{\mathrm{F}}} \simeq \frac{1}{4}
$$

and

$$
\begin{aligned}
& \delta=\frac{d_{\text {ox }}}{d_{\text {flaw }}} \simeq 4 \\
& E_{F}=5.10^{6} \mathrm{~V} / \mathrm{cm} .
\end{aligned}
$$




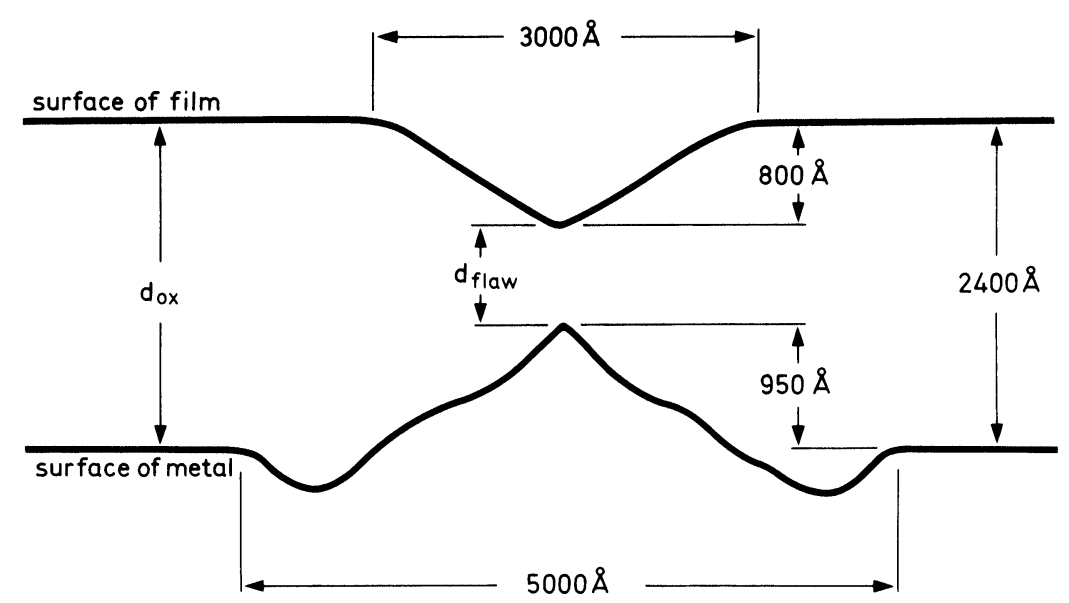

FIGURE 14 Diagram of a cross-section of a flaw in a $2400 \AA \mathrm{Ta}_{2} \mathrm{O}_{5}$ film, after Vermilyea. ${ }^{9}$

This equation enables the ratio $\mathrm{V} / \mathrm{V}_{\mathrm{w}}$ in the curve of mean-life time to be transformed into electric field strength. The transformation function was checked by using results given by Burnham ${ }^{6}$ of recent accelerated life test measurements on Kemet solid tantalum capacitors of $3,3 \mu \mathrm{F}, 20 \mathrm{~V}$. Figure 15 gives the Weibull plots for two different test lots, one lot having a $\mathrm{V} / \mathrm{V}_{\mathrm{w}}$ ratio of 2,45 and the other lot having the ratio 2,35 . Taking the $63 \%$ value for each lot from Figure 15, using electric field strength values calculated from Eq. (5) (with $\mathrm{V}_{\mathrm{w}} / \mathrm{V}_{\mathrm{F}}=1 / 5, \delta \simeq 4$ ), and transferring the two points thus obtained to Figure 13 shows reasonable agreement with the $85^{\circ} \mathrm{C}$ line.

By measuring the maximum breakdown voltage of a capacitor, and knowing the forming voltage and oxide thickness, the flaw thickness can be obtained

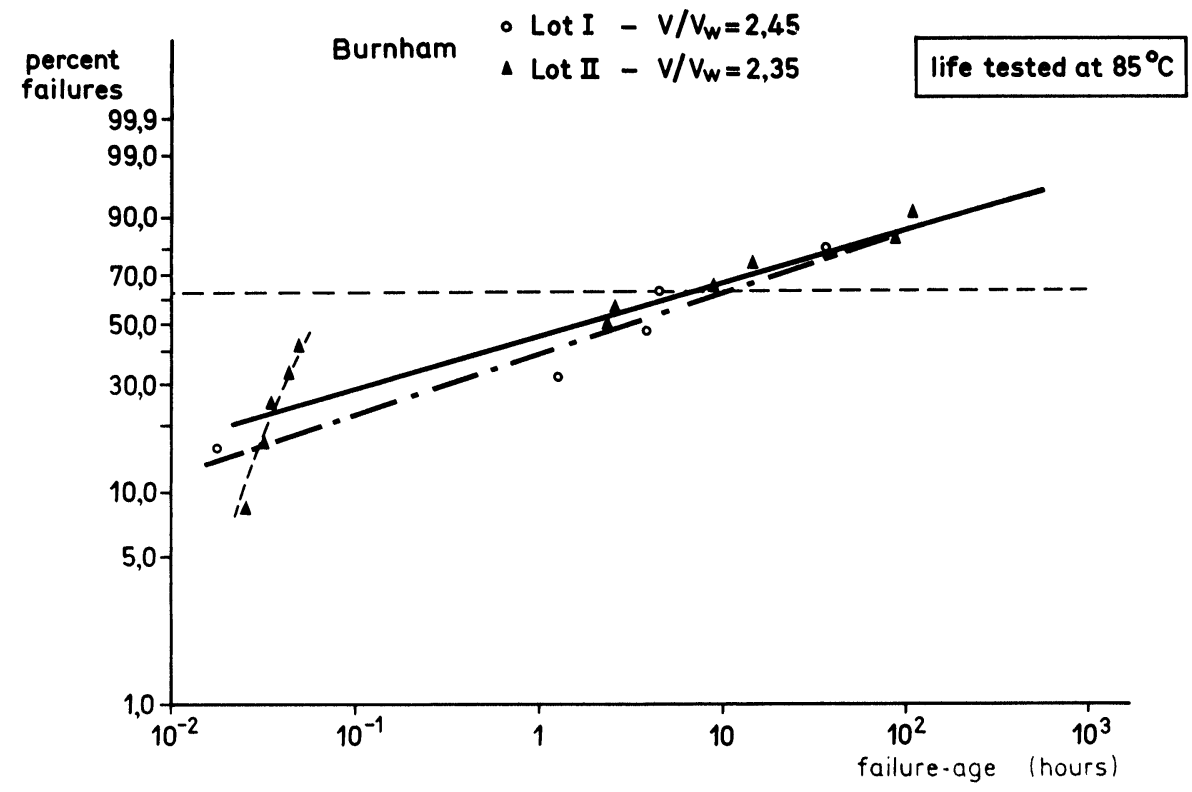

FIGURE 15 Weibull plots of $3,3 \mu \mathrm{F}, 20 \mathrm{~V}$ tantalum chip capacitors of different lots, life-tested at $85^{\circ} \mathrm{C}$ with $\mathrm{V} / \mathrm{V}_{\mathrm{W}}$ of 2,35 , as measured by Burnham. 
from Eq. (5). This, in conjunction with Figure 13, enables the mean-life time of solid tantalum capacitors to be determined.

Using Eq. (4) to obtain values for a (the distance from the equilibrium position to the top of the potential barrier), calculated from the slope of the line and with $q=5 \mathrm{e}$, gives:

$$
\begin{array}{ll}
\text { for } 85^{\circ} \mathrm{C}: & \mathrm{a}=1,36 \AA \\
\text { for } 125^{\circ} \mathrm{C}: & \mathrm{a}=1,28 \AA
\end{array}
$$

and, for $\mathrm{E}=7,5 \times 10^{6} \mathrm{~V} / \mathrm{cm}$, the activation energy $\mathrm{Q}$ is $1,2 \mathrm{eV}$. From results of field crystallization growth rate of wet tantalum systems, Vermilyea ${ }^{8}$ reported values for a and $\mathrm{Q}$ of $1,6 \AA$ and $1,2 \mathrm{eV}$ respectively; Gulbransen and Andrew ${ }^{10}$ give an activation energy of $1,2 \mathrm{eV}$ for oxidation of tantalum at temperatures at which crystalline oxide is formed.

\section{CONCLUSIONS}

The results of accelerated life test measurements, together with the electron micrographs, support the propositions that:

- Failure of solid tantalum capacitors is due to field crystallization;

- the life time of the capacitor is determined by the crystal growth rate;

- the time required for crystal growth to the critical size at which the film cracks is an exponential function of field strength.

There will be some influence on field crystallization due to the anodization conditions, but any error introduced is small and would be negligible in these calculations. Although the electron microscopy evidence presented is mainly in terms of structures with $\mathrm{Au}$ counter-electrodes, there is evidence that field crystallization can start in commercial $\mathrm{MnO}_{2}$ counter-electrode capacitors because of the following -

1) Capacitors with gold or $\mathrm{MnO}_{2}$ cathodes are both so-called "dry" capacitors and in both there is humidity access from the air.

2) Photographs of crystals on anodized tantalums made by Vermilyea (wet conditions), Burnham $\left(\mathrm{MnO}_{2}\right.$ cathode) and (gold-electrode) are very similar.

3) Calculations of the activation energy of the field-crystallization on tantalum, made by Vermilyea, are very much in line with the results obtained in the present paper for commercial capacitors.

\section{REFERENCES}

1. B. Kleindienst, Internationale Elektronische Rundschau 8, 205 (1970).

2. G. H. Didinger, Kemet Engineering Bulletin, (January 1961).

3. G. H. Didinger, Evaluation Engineering 6, (Sept/Oct. 1964).

4. L. F. Howard and A. W. H. Smith, Proc. Electronics Components Conference 14, 187 (1964).

5. J. Burnham, Proc. Electronics Components Conference 21, 314 (1971).

6. J. Burnham, Proc. Electronics Components Conference 23, 111 (1973).

7. D. A. Vermilyea, J. Electrochemical Society 102, 207 (1955).

8. D. A. Vermilyea, J. Electrochemical Society 104, 542 (1957).

9. D. A. Vermilyea, J. Electrochemical Society 110, 250 (1963).

10. E. A. Gulbransen and K. F. Andrew, J. Electrochemical Society 96, 364 (1949). 

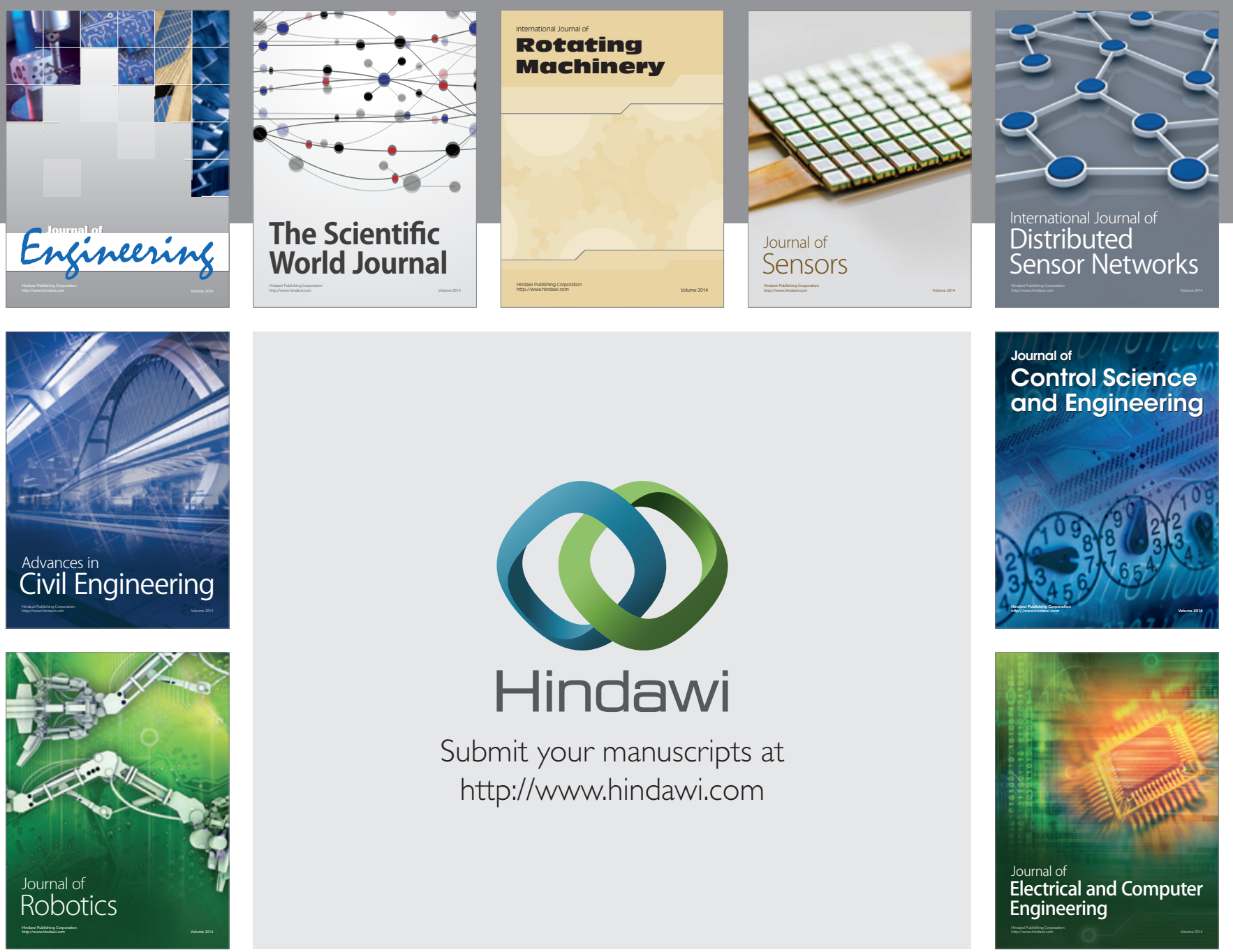

Submit your manuscripts at

http://www.hindawi.com
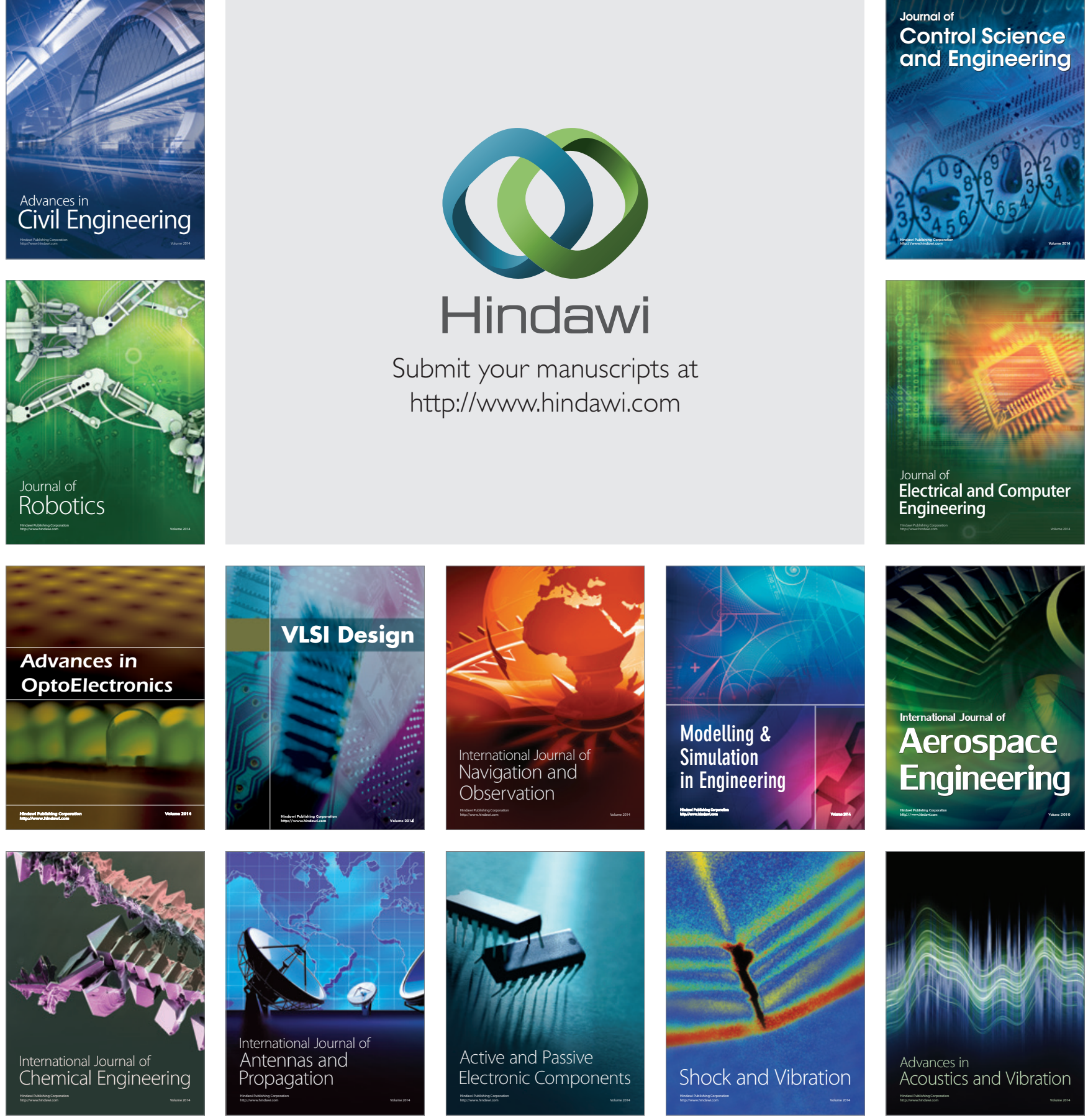